\title{
Could Pam Reynolds Hear? A New Investigation into the Possibility of Hearing During this Famous Near-Death Experience
}

\author{
Gerald M. Woerlee, M.B.B.S. (Western Australia), \\ FRCA (London) \\ Leiderdorp, The Netherlands
}

\begin{abstract}
The well-known Pam Reynolds near-death experience (NDE) occurred at the Barrow Neurological Institute during a medically well-documented period, which is why many people regard it as proof of the reality of a separable immaterial conscious mind. In this article, I use information from related publications from the Barrow to fill in lacunae in the published medical documentation of this apparently amazing NDE. Furthermore, I present the case that the four veridical auditory perceptions Reynolds reported can be explained by her ability to hear during periods of conscious awareness while under the influence of the combination of drugs employed to provide general anesthesia during the operation on her giant basilar artery aneurysm.
\end{abstract}

KEYWORDS: Pam Reynolds, anesthesia awareness, hearing, near-death experience, consciousness

The veridical aspects of the extraordinary near-death experience (NDE) that Pam Reynolds reported are often cited as proof of the reality of a separate immaterial conscious mind or non-local consciousness. Reynolds underwent a major neurosurgical operation to remove a basilar artery aneurysm under general anesthesia and hypother-

Gerald M. Woerlee, M.B.B.S. (Western Australia), FRCA (London), is an anesthesiologist affiliated with the Rijnland Hospital in Leiderdorp and Alphen aan den Rijn, The Netherlands and an affiliate associate professor to the Department of Anesthesiology, Leiden University Medical Centre, Leiden, The Netherlands. He is author of the books Mortal Minds (2003, Prometheus Books) and The Unholy Legacy of Abraham (2008, Booklocker). Communications regarding this article should be sent to Dr. Woerlee at email: gerry@woerlee.org. 
mic cardiac arrest. After awakening, she reported hearing a veridical sound, a verbal exchange, as well as music played during the course of her operation while she was apparently unconscious under general anesthesia. The circumstances surrounding this operation were such that this ability to hear actual speech and sounds were apparently inexplicable with normal hearing or other physical explanations. But is this true? In this article, I examine whether the veridical verbal exchanges, sounds, and music that Pam Reynolds reported were the result of normal hearing.

A quick recapitulation of this well-known story recounted in cardiologist and NDE researcher Michael Sabom's (1998, pp. 37-82) book Light \& Death will aid the reader to place the sounds, speech, and music in their proper context. The surgery took place in August, 1991, at the Barrow Neurosurgical Institute in Phoenix, Arizona, USA. The lead surgeon was Robert Spetzler, an eminent neurosurgeon with internationally acknowledged expertise in this type of surgery. Reynolds was conscious when brought into the operating theater (Sabom, 1998, p. 38) and was subsequently put under general anesthesia. In addition to normal clinical anesthesia monitoring, the surgical team monitored her level of consciousness using Brainstem Auditory Evoked Potentials (BAEPs), measurement of the response of her brainstem to 100 $\mathrm{dB}$ clicking sounds applied to both ears through molded earphones placed in her ear canals and fixed firmly in place with tape. Spetzler commenced the operation after completion of all the necessary preparations. He first opened her scalp and subsequently used a pneumatic drill to make an initial hole in her skull to introduce the specialized bone saw. Reynolds later reported that it was at this moment that she made her first veridical observation: "The next thing I recall was the sound: It was a natural D. As I listened to the sound, I felt it was pulling me out of the top of my head" (Sabom, 1998, p. 41).

Having drilled this initial hole in Reynolds' skull, Spetzler was able to use a pneumatic bone saw to make a sufficiently large opening through which to operate upon her aneurysm. Pneumatic bone saws are usually very noisy, as Reynolds noted:

I heard the saw crank up. I didn't see them use it on my head, but I think I heard it being used on something. It was humming at a relatively high pitch and then all of a sudden it went Brrnrrrrrr! like that. ... (Sabom, 1998, p. 41)

Exposure of the aneurysm revealed it to be too large for a conventional operation, so the cardiothoracic surgeon was asked to insert 
cardiopulmonary bypass tubing into Reynolds' femoral (groin) blood vessels. At this point cardiovascular surgeon Murray encountered a problem with the blood vessels in Reynolds' right groin. Reynolds later reported having heard Murray's comments:

Someone said something about my veins and arteries being very small. I believe it was a female voice and that it was Dr. Murray, but I'm not sure. She was the cardiologist [sic]. I remember thinking that I should have told her about that ... (Sabom, 1998, p. 42)

Murray subsequently successfully inserted the bypass tubing into the vessels of Reynolds' left groin, after which the operation proceeded successfully. Reynolds later reported that towards the end of the operation, after the cardiopulmonary bypass was terminated and while her wounds were being closed, she heard a verifiable piece of music. As Sabom (1998) reported it,

The music in the background began playing rock as Spetzler's younger assistants took over the closing surgical duties. The songs did not escape Pam's notice:

When I came back, they were playing "Hotel California" and the line was "You can check out anytime you like, but you can never leave." I mentioned [later] to Dr. Brown that that was incredibly insensitive and he told me that I needed to sleep more. [laughter] When I regained consciousness, I was still on the respirator.

Spetzler's surgical report indicates that at 2:10 P.M. the "patient was taken to the recovery room still intubated, but in stable condition." (p. 47)

These are the four verifiable fragments of sounds, music, and speech that Reynolds reported subsequent to recovering evident consciousness and the ability to speak. The fact that she reported only these things subsequent to recovering consciousness and the ability to speak indicates she had explicit long-term memories of these perceptions. She first came into contact with Sabom in 1994. He subsequently published a quite thorough account of her story in his 1998 book. Aside from a recreation of the episode in a BBC documentary, including interviews with Reynolds, Sabom, and Spetzler (Broome, 2002), Sabom's account remains the primary source material for the worldwide interest in this report of a seemingly astonishing experience.

Could Reynolds have actually heard all these things with normal physical hearing, or are these four veridical perceptions and observations proof of perceptions made by her immaterial conscious mind 
while separated from her body during her NDE? After all, the monitors indicated she was unconscious under general anesthesia at the time, and during the first three observations her consciousness was apparently separated from her body during an out-of-body experience (OBE). Because Reynolds' OBE began with the first sound she heard, I will first discuss whether her apparently disembodied conscious mind could have heard any of these events, speech, or music.

\section{Inability of a Separated Immaterial Consciousness to Hear Sound Waves}

Many people seldom question how a disembodied consciousness can see normal light waves or hear the sounds of speech and other things during an OBE. This article is about the veridical sounds Pam Reynolds reported having heard, so I will confine this discussion to examining whether an apparently disembodied immaterial mind can hear sounds during an OBE.

A logical discussion on this matter begins with an examination of the properties of an apparently disembodied immaterial conscious mind. Very few formal studies of all the properties of the immaterial conscious mind believed to separate from the body during OBEs and NDEs have been published (Tiberi, 1993; Woerlee, 2005c). Some of the most illuminating relevant information comes from reports of spontaneous OBEs. One such report published by Kenneth Ring and Madelaine Lawrence (1993) is particularly striking. During 1985, a woman reported the following experience of an OBE she underwent as part of an NDE while she was a patient at Hartford Hospital in Hartford, Connecticut. Nurse Kathy Milne reported that the woman

told me how she floated up over her body, viewed the resuscitation effort for a short time and then felt herself being pulled up through several floors of the hospital. She then found herself above the roof and realized she was looking at the skyline of Hartford. She marveled at how interesting this view was and out of the corner of her eye she saw a red object. It turned out to be a shoe. . . (Ring \& Lawrence, 1993, p. 226)

A study of the history of the Hartford Hospital up to 1985 reveals a relatively new hospital with brick and concrete walls and, more importantly, very hard and solid reinforced concrete floors. So the apparently disembodied conscious mind of this woman passed without effort through several reinforced concrete floors. 
Sound waves transmitted through air are no more than variations in air pressure causing the tympanic membranes in the ears to move to and fro in response to these pressure variations. These movements are transmitted to the cochlea in the inner ear, which translates these pressure variations into nerve impulses perceived as sound.

If a disembodied conscious mind can pass through several concrete floors without experiencing any apparent resistance, then it will certainly not interact in any way with the infinitely less solid air pressure variations of sound waves in air caused by speech or music. Accordingly, an apparently disembodied conscious mind is unable to hear sound waves in air. The veridical sounds of apparatus and music are most definitely not telepathically perceived, nor are they clairvoyantly perceived with any form of paranormal perception. Gambling casinos, and the experiences of the countless millions of dead and living blind and deaf people, are proof that such perceptions do not exist (Woerlee, $2004,2005 a)$. This means that all veridical sounds heard in the vicinity of a person undergoing an OBE are perceived by means of hearing with the ears of that person. But was it possible for Pam Reynolds to physically hear anything, and was she conscious and able to remember them?

\section{Intact Sensation During General Anesthesia}

Studies since the late 1970s have revealed that the brains of people under general anesthesia respond to sensations such as touch, movements, light, sound, and pain (Thornton 1998). So the brains of people undergoing general anesthesia do register the sounds and sensations in their vicinity-but very few people remember these things. What this actually means is that adequate general anesthesia blunts the responses of the body to these stimuli, as well as removing the implicit and explicit memories of events occurring during surgery (Andrade, 2005; Iselin-Chaves, 2005; Jones, 1994; Kerssens, 2005). But could Reynolds have heard or perceived any sounds above the 100-decibel clicking sounds applied to her ears through the molded earphones (Sabom, 1998, p. 39)?

\section{The "Clicking" Stimulus Parameters}

This question brings us to a discussion of the parameters of these 100-decibel clicking sounds applied at a rate of 11.3 clicks per second. Indeed, 100 decibels is very loud, equivalent to an orchestra at its 
loudest. I have even heard of one person who listened to music through earphones at an intensity of 100 decibels. He heard absolutely nothing of what happened around him or what was said to him. Many people do just as this man: They imagine these clicking sounds are similar to loud 100-decibel music. Accordingly, they claim these clicking sounds were so loud that they drowned out all chance of Reynolds physically hearing other sounds, speech, or music. These same people then argue that therefore she must have heard these sounds by some other paranormal means. But is this reasonable or true?

Unfortunately, Sabom's (1998) account of the Reynolds case is nontechnical, so any answer to this question requires an examination of the monitoring techniques Spetzler and his colleagues used during Reynolds' surgery. Hypothermic cardiac arrest is a technique developed in the 1950s and in use ever since for various cardiac-, vascular-, and neuro-surgical purposes (Matalanis, 2003; Spencer, 1962). Reynolds was not the first person ever to undergo hypothermic arrest for an operation on her basilar artery aneurysm. In 1988, Spetzler and his colleagues published a detailed account of the anesthetic, operative, and monitoring procedures used to perform the same operation upon seven patients with giant basilar artery aneurysms (Spetzler, Hadley, Rigamonti, Carter, Raduzens, Shedd, \& Wilkinson, 1988). As Sabom (1998) indicated, the surgical team used the same surgical procedure with Reynolds, so the article by Spetzler's group provides invaluable supplementary information regarding the duration and nature of these clicking sounds:

The BAEP's are recorded by far-field techniques following broad-band click stimuli (100 $\mu$ sec rectangular pulse monophasic square waves) delivered via molded ear speakers (Fig. 2). Clicks of alternating polarity are used at stimulus levels of 90 to $100 \mathrm{~dB}$ (sound pressure level) at rates of 11 to 33/sec. (Spetzler et al., 1988, p. 869)

The duration of the BAEPs induced by these clicking sounds is clearly indicated in Figure 2 of the same article: they last no more than 12 milliseconds (Spetzler et al., 1988, p. 869).

What this all means is that at a rate of 11.3 clicks per second, a total time equal to $11.3 \times 100=11,300 \mu \mathrm{sec}=11.3$ milliseconds per second was occupied by these clicking sounds. This means that for each second, only $11.3 / 1000=0.0113$ second, or a little more than one 100 th of each second was occupied by these clicking sounds.

The next matter to consider is the brainstem activity aroused by these clicking sounds. According to Spetzler et al. (1988), the dura- 
tion of each evoked BAEP signal is about 12 milliseconds. At a rate of 11.3 clicks per second, this means these clicking sounds generated brainstem activity lasting a total time equal to $11.3 \times 12=124,6$ milliseconds $=0.1246$ seconds of brainstem activity per second.

These calculations mean that each second, Reynolds' brainstem had somewhere between $1-0.1246=0.8754$ second to $1-0.0113=$ 0.9887 second to perceive other sounds. Put another way, these clicking sounds occupied at most only $12.46 \%$ of her hearing and brainstem processing capacity. This duration left her with more than sufficient time and neural capacity to perceive other sounds. Indeed, the parameters of these clicking sounds explain why nowhere in Sabom's (1988) account does Reynolds report hearing these clicking sounds. These parameters indicate they were no more than an ignored background noise. So if she was conscious, the parameters of these sounds enabled normal hearing of other sounds, speech, and music.

The clicking sounds were administered to only one ear, with a masking sound in the opposing ear (Spetzler et al., 1988). Such a masking sound consists of white noise. In 1982, the Barrow Neurosurgical Institute's Neurophysiology Department published a set of BAEP stimulation and white noise parameters (Raudzens, 1982), and these more or less unchanged parameters were in still use by other neurosurgeons during 2009, long after Reynolds' operation (Bond, 2010). The click stimulus was as described above, and the masking noise consisted of continuous white sound in the other earplug at a level of 40 decibels (Bond, 2010; Raudzens, 1982).

Normal human speech at a distance of one to two meters has a loudness level of 60-70 decibels, and people typically listen to music at levels of 70-85 decibels. Consequently, neither the clicking sounds with the parameters described above nor the continuous white sound at a 40-decibel level preclude hearing with bone or air conduction. (An addendum to this article describes a hearing test that readers can perform. This test involves similar auditory stimulation parameters as were used to elicit BAEPs during Reynolds' operation. The test clearly demonstrates that Reynolds was able to hear the sounds of speech and music despite this auditory stimulation.)

\section{The Earphones}

The earphones in Reynolds' surgery were molded earphones fitted in her ear canals and taped in place. This description actually indicates 
nothing about whether or not it was possible to hear external sounds in spite of these earphones. After all, earplugs and earphones differ considerably in their sound-excluding properties. Previous publications also indicate nothing about the sound-excluding properties of these earphones (Raudzens, 1982; Spetzler et al., 1988). Consequently, it is possible to state only that these earphones may not have been efficient at excluding sound transmitted through air, such as speech or music.

Regardless of the sound excluding properties of earphones, no earphone or earplug blocks bone conduction of sound through the bones of the skull. All this information means that Reynolds would hear bone conduction of sounds above a level of 40-50 decibels.

\section{The BAEP Signals Indicating Reynolds Was Unconscious}

All discussions emphasize the importance and the implicit belief in the accuracy of the BAEP signals used to indicate Reynolds' level of unconsciousness, or depth of anesthesia. Sabom's (1988) account of the Reynolds experience revealed that the surgical team used BAEPs to determine her level of consciousness throughout the duration of her operation (p. 45). However, is the BAEP an infallibly accurate measure of the depth of anesthesia and the absence of consciousness?

Since the late 1970s, various parts of the BAEP waveform have been used and studied intensively as a measure of the absence of consciousness and depth of anesthesia. At the time of Reynolds' operation, the BAEP was evaluated manually, a technique that, even in the hands of experts, is now known to be prone to error (Schneider, 2003). Moreover, there is considerable interpersonal variability in BAEP interpretation, and isolated forearm studies reveal it does not always indicate loss of consciousness (Loveman, 2001). This is the reason why the American Society of Anesthesiologists (ASA) issued a practice advisory during 2006 in which they advised against sole reliance on a single electronic measure of awareness such as the BAEP (ASA, 2006).

All this information indicates that sole reliance upon the BAEP as a measure of loss of consciousness and depth of anesthesia was an errorprone technique, even though it often, but not always, provides a correct answer. A BAEP indicating loss of consciousness during general anesthesia did not and does not exclude the presence of consciousness or awareness. So was there any other way the anesthesiologists could have determined the presence or likelihood of consciousness during Reynolds' general anesthetic? 


\section{Reynolds' Awareness During General Anesthesia}

During 1991 and continuing to the present time, anesthesiologists have used a combination of parameters to determine the absence or presence of awareness during general anesthesia. No single measure is an absolute indicator of the presence of consciousness, unless of course the patient sits up and is evidently conscious. Electronic measurements of brain activity such as the Bispectral Index, BAEPs, and Spectral Edge are employed, but none are 100\% accurate measures of the absence or presence of consciousness (ASA, 2006). Consequently, they are always used in combination with clinical signs such as sudden increases in pulse rate, unexplained variable pulse rate, sudden increases of blood pressure, sweating, lacrimation, widening of the pupils, and suspicion based upon experience (the "fingerspitzgefühl" of experienced practitioners). These monitoring processes were the reality at the time of Reynolds' operation and are still the daily reality of every anesthesiologist. Spetzler et al. (1988) also published details of the general anesthetic technique used at the time.

A sleep dose of either barbiturate (thiobarbiturate at $3 \mathrm{mg} / \mathrm{kg}$ body weight) or midazolam $\mathrm{HCl}(0.1 \mathrm{mg} / \mathrm{kg})$ is administered slowly with oxygenation. Narcotics such as sufentanil and nondepolarizing muscle relaxants such as vecuronium bromide effectively reduce any sympathetic response to anesthesia induction and prevent undesirable cardiovascular changes. ... Anesthesia is maintained with incremental doses of narcotics and is supplemented by a mixture of nitrous oxide and oxygen or isoflurane with nitrous oxide and oxygen to maintain stable cardiovascular parameters and an adequate level of anesthesia. (p. 870)

Sabom's (1998) report of the Reynolds story partially indicated that this was the general anesthetic technique that Spetzler and his team had used. This was a perfectly normal general anesthetic technique at the time of Sabom's writing and was also standard at the time of Reynolds' operation, so there was no reason for the Spetzler group to change the technique between 1988 and 1991. This general anesthetic technique described was in common use worldwide. I have personally administered several thousand general anesthetics with this drug combination during this time period. It was a very useful drug combination, but just as with many other general anesthetic techniques, some people reported post-surgery that they had been conscious and aware at some point during general anesthesia with this technique even though they had given no sign of being aware. 
At the time of her verifiable perceptions, Reynolds was under general anesthesia. However, she was not on cardiac bypass at these times (Holden, 2006; Woerlee, 2004, 2005a, 2005b), and her body temperature was presumably above 34 degrees Celsius (Spetzler et al., 1988, p. 870). The incidence of awareness during general anesthesia varies somewhat depending upon the type of surgery and anesthetic technique, varying between 1 to 9 per 1000 general anesthetics (Ghoneim, 1992; Orser, 2008). Not all of these awareness experiences during surgery performed under general anesthesia are painful or associated with anxiety (Sebel, Bowdle, Ghoneim, Rampil, Padilla, \& Domino, 2004, p. 835). An extensive meta-analysis of all adequate prospective studies of anesthetic awareness under general anesthesia reveals that about $40 \%$ of patients reporting awareness during general anesthesia are calm, peaceful, even serene during their awareness experiences and that about $0.7 \%$ of people report undergoing an OBE as part of their awareness (Table 8 in Woerlee, 2011).

\section{The Barbiturate Burst-Suppression}

Many non-anesthesiologist readers may be confused by Sabom's (1998, p. 38) statement that Reynolds was administered pentothal at 7:15 a.m. alongside Spetzler et al.'s (1988, p. 870) statement that she would also have been administered a barbiturate infusion to reduce the metabolism of her brain. Pentothal is a common name for a drug still commonly used in anesthesia and used almost ubiquitously during 1991. Its other names are thiopental in the USA and thiopentone in the UK. It is a short-acting barbiturate drug of the class of thiobarbiturates.

Anesthesia was induced with thiopental. This was common procedure during 1991. As Spetzler correctly explained in the quote above, the usual dose was about $3 \mathrm{mg} / \mathrm{kg}$ body weight. A dose somewhere between $200-350 \mathrm{mg}$ is usually enough for a woman. This initial dose is a single dose. It is administered to induce sleep, and the sleep induced by such a single dose of thiopental lasts about 10 minutes. Sleep and anesthesia was subsequently maintained with a mixture of gases: oxygen, nitrous oxide, and isoflurane. A muscle-paralyzing drug called vecuronium was given, as was a powerful morphine-like drug called Sufentanil.

This combination of drugs is what Sabom (1998, p. 38) referred to. Spetzler et al. also mentioned a subsequent infusion of barbiturate to induce suppression of electroencephalographic (EEG) burst activity, but did not specify when this administration commenced. He simply 
stated: "Barbiturate-induced EEG burst suppression for cerebral protection is maintained intraoperatively" (Spetzler et al., 1988, p. 870). Fortunately, another article that Spetzler coauthored on the topic of operations performed upon giant intracranial arteriovenous malformations revealed the timing: "Once the dura mater is opened, barbiturates are given and titrated until EEG burst suppression is achieved" (Han, O’Neill, \& Spetzler, 2003, p. 96).

An infusion of barbiturate for purposes of burst suppression is always done with thiopental. The effect of burst suppression with thiopental is to cause flattening of the EEG (isoelectric EEG) but does not cause the BAEPs to disappear (Drummond, 1985). But the effect of an infusion of thiopental is not instantaneous; it takes more than 20 minutes to achieve an isoelectric EEG (Drummond, 1985). But this is not the whole story. Reynolds was attached to a cardiac bypass machine. Such a machine is filled with a reservoir of priming fluid the composition of which is similar to blood plasma without the proteins. This solution dilutes the hemoglobin concentration of blood to a hematocrit of about 28-30\%, reducing blood viscosity (Spetzler et al., 1988, p. 870). Such dilution of the hemoglobin also reduces the circulating concentrations of all anesthetic drugs, reducing the effect of the thiopental infusion administered for EEG burst suppression, as well as the effects of other anesthetic drugs. Indeed, Spetzler mentioned that up to four liters of priming solution were sometimes required in the cardiopulmonary bypass circuit (Spetzler et al., 1988, p. 870), and this intervention is known to cause the plasma concentrations of opiates, anesthetic gases, and thiopental to decrease by up to $20-50 \%$ upon commencement of cardiopulmonary bypass (Gedney \& Ghosh, 1995). The proof of this effect was revealed in Sabom's (1998) account where he stated that Reynolds' EEG flattened only after her heart arrested: "As Pam's heart arrested, her brain waves flattened into complete electrocerebral silence. Brain-stem function weakened as the clicks from the ear speakers produced lower and lower spikes on the monitoring electrogram" (p. 43). In other words, true burst suppression, or electrocerebral silence, occurred only after cardiac arrest. All this information means Reynolds' brain was not affected by massive doses of barbiturates at the time of her verifiable perceptions. This information explains why sufficient awareness was possible for Pam Reynolds to hear the drill, the saw, and Murray's comment.

The barbiturate infusion was terminated during the period of cardiac arrest, possibly started again upon restoration of circulation, but certainly terminated before the end of surgery. Reynolds was allowed 
to awaken spontaneously in the intensive care unit (Han, 2003; Spetzler, 1988). After termination of such a thiopental infusion insufficient to cause electrocerebral silence, the plasma and brain concentration of barbiturate drops reasonably rapidly. When one considers the operative technique and its timing, the total duration of the barbiturate infusion cannot have been longer than about 60-90 minutes (see Chapter 3 in Sabom, 1998 for the timing of the procedure). When one considers this point, plus the secondary elevation of cardiac output caused by the administration of sodium nitroprusside to improve rewarming (Spetzler, 1988), one can conclude that the context-sensitive half-life of the thiopental remaining in her body cannot have been long. Context-sensitive half-life is the plasma half-life of a drug after termination of an infusion of that drug (Hughes, Glass, \& Jacob, 1992). It is the result of a complex of factors such as the pharmacokinetic properties of the drug, the duration and dose of the infusion, cardiac output, and genetic and other individual variations. For example, a common observation among anesthesiologists is that women generally awaken more rapidly than men from general anesthesia (Buchanan, Myles, \& Cicuttini, 2011). All these factors, together with the likely short duration of the context-sensitive half-life of the administered thiopental, means that Reynolds could very well have been conscious during the time that the song Hotel California was playing.

\section{Could Pam Reynolds have been aware?}

Could Pam Reynolds have been aware without the anesthesiologist knowing of her awareness? The answer is yes. Her body temperature during all the periods of verifiable perceptions of sounds, speech, and music was nearly normal. Her head and neck were totally draped for surgery on her brain, her chest was draped in case an emergency heart operation was needed to restart her heart, and her groins were draped for insertion of bypass tubing in either left or right groin. The anesthesiologist had no access to her body to determine the presence of movements, sweating, lacrimation, or widening of the pupils. The only clinical measures of consciousness were pulse rate, blood pressure, and the BAEP, none of which are individually reliable. Moreover, her blood pressure and pulse rate changes were suppressed to a large degree with the opiate Sufentanil. So the only real certainty-if one can call it that - that she was unconscious was the general efficaciousness of the general anesthetic technique, the anesthesiologist's experience, 
and the sometimes-fallible BAEP. Thus, it is very reasonable to conclude she may have been conscious at the time. And her observations and perceptions revealed she was conscious at the time of perceiving the veridical sounds, speech, and music. This brings us to the effects of anesthetic drugs on mental processes.

\section{Anesthetic Drugs and Mental State During Awareness}

Many people seem to think, and write, as if all drugs used during anesthesia have an "all-or-nothing" effect in each person, always causing exactly the same effects in each person, and have an identical dose-brain concentration effects on each person. This is absolutely incorrect. There is considerable variation between people in the doseconcentration-related effects of each anesthetic drug and gas. A quick perusal of the statistical variation data of the vast pharmacokinetic and pharmacodynamic datasets of anesthetic drugs reveals this fact. Therefore, a combination of drugs sufficient to cause general anesthesia in nearly all people does just that: It is sufficient in nearly allbut not all-people. This fact is why some people report experiencing awareness episodes during general anesthesia. Furthermore, surgical stimuli can also arouse awareness in some people under general anesthesia. This process is a bit like shaking a sleepy person awake. There is a considerable anesthesiology literature on all these phenomena.

Moreover, and more importantly, a person experiencing awareness during general anesthesia still experiences mental effects induced by the drugs used to provide general anesthesia. It is documented that Reynolds received nitrous oxide, an opiate (Sufentanil), and the gas Isoflurane. What is known of the effects of low concentrations of these drugs in conscious persons?

I will begin with nitrous oxide. Since the time of Humphrey Davy and his "hilarious evenings" in Bristol during 1800, nitrous oxide has been renowned for its pleasurable mental effects (Davy, 1800). But nitrous oxide does not only cause pleasurable effects. For example, Peter Fenwick, a neurophysiologist, described his own experiences of nitrous oxide inhalation. When a young man, he took part in an experiment during which he had to perform certain tasks while breathing $40 \%$ nitrous oxide in oxygen. He reported his experiences of the mental effects of nitrous oxide. 
The world suddenly became full of meaning, and I knew that I had obtained a universal symbol which contained all knowledge. When I completed the experiment and as the mask was taken from me I called to my colleagues, I have it! The answer to all knowledge! And I held up two fingers in a V sign. (Fenwick, 1996, p. 306)

These sensations of enhanced awareness and increased mental capacity that Fenwick described are not new. Humphrey Davy (1800, pp. 487-489) and William James (1896, para. 295), among many others, described them beautifully. This mental enhancement was the reason for the popularity of nitrous oxide demonstrations provided by travelling showmen in the rural USA during the 19th century. Nitrous oxide is also a powerful analgesic drug, a 10\% concentration being equivalent to 10 milligrams of morphine. During the late 1980s and early 2000s, nitrous oxide was a common adjuvant gas in anesthetic gas mixtures, commonly being administered at a relative concentration of about $65 \%$.

Reynolds also received the powerful opiate drug Sufentanil. During any period of awareness during general anesthesia she will also have experienced the mental effects of this drug. Sufentanil has the same effects as all opiates. The effects of opiates in conscious persons are variable due to genetic differences (Dahan, 2008). Curiously, very few modern studies address the sensations and emotions aroused by opiates. The few published studies reveal that, with the same opiate dose, $40 \%$ of people feel euphoric and 50\% feel dysphoric (Lasagna, 1955). Other experiences such as sensations of floating, warmth, sleepiness, and dizziness are related to age and to brain opiate concentration (Haba, 2011). In the absence of modern research, the best sources of information about the very wide range of sensations, experiences, and emotions aroused by opiate injection are the almost-poetical descriptions published more than a century ago. In a book published in 1895, a physician from the same period related his personal experiences of the effects of morphine he injected subcutaneously to relieve his exhaustion.

I say dreams, because there was one after another, and one chased into the other; then they would get mixed up in a queer fashion, but they were all delightful and bewitching. Now, I was in the midst of flowers whose fragrance fairly intoxicated me; then among airy-like structures, whose towers and minarets pierced the crimson and purple cloud islands that floated high in a sky of deepest blue. Forms of enchanting loveliness passed in and out, while music from unseen voices was as the songs of angels. The scene changed rapidly without shock to my highly sensitized nerves; the impossible and unusual be- 
came substantial and natural. I stood on an island of emerald green, looking out upon an opalescent sea of sublime tranquility, upon which men of stately mien walked as upon dry land; then I was suddenly transferred to a mountain peak, where I saw all the kingdoms of the world, with their pleasures and riches, without a suggestion of the sorrows and afflictions that beset humanity. I saw the faces of loved ones lit up with ineffable happiness as they pleasantly conversed with me; it did not occur to me until after the waking that these were the forms of those who had been called hence during my childhood, youth, and younger manhood. They were living and real; yet their manner and speech were not those of the living. These and a thousand other visions floated before the dream eyes of the quickened but disordered brain; but the sensations were in the highest degree pleasurable and the delirium was one of ever-changing joy. (Cobbe, 1895, p. 103-104)

So opiates can also induce hallucinations of transcendence, of tranquility, of meeting deceased relatives, etc. These are reported time and again in older reports of opiate effects and are the reasons why these drugs are so pleasant as drugs of addiction.

Finally, there is the matter of isoflurane concentrations insufficient to cause unconsciousness. Isoflurane is no different from any other gaseous anesthetics. At concentrations insufficient to cause unconsciousness, these drugs can induce a calm and peaceful state in which the patient is free of pain and can cooperate with the surgeon (Artusio, 1954).

There is a vast literature describing the mental states induced by drugs used to provide general anesthesia, and this is but a short introduction. But even this short introduction suffices to demonstrate that the mental states Reynolds described during her extraordinary experience could just as well have been due to the effects of the drugs used during her general anesthetic upon the functioning of her brain during periods of awareness.

\section{Explanation of Hearing Veridical Sounds, Speech, and Music}

The OBE is a perception of, but not actual, disembodiment of the conscious mind and is a subject of much neurophysiological research (see Pubmed for many, many excellent studies). Moreover, I contend that the "missing dentures case" also conclusively proves the OBE to be a sensation of disembodiment rather than actual disembodiment of the conscious mind (Woerlee, 2010). The fact that people feel pain during 
OBEs also indicates these experiences are perceptions of bodily sensations rather than anything else (Tiberi, 1993; Woerlee, 2010). Highly inaccurate descriptions of events during OBEs point to the same conclusion, such as a person who described viewing from an OBE point of view how their body jumped up to two feet in the air as a result of the electric shock of cardioversion (Sabom, 1982, pp. 45, 125, 213). There is no muscular mechanism or physical possibility by which such a two foot jump—or even a one millimeter jump, for that matter-could occur as a result of an electrical shock applied to the chest. I suggest that all such observations prove OBEs are not due to disembodiment of a separate conscious mind but are, rather, remembered perceptions of bodily sensations. I contend that these facts, in conjunction with the observation that a disembodied conscious mind able to pass through concrete floors cannot possibly hear sound waves in air, prove that Pam Reynolds heard these veridical sounds, speech, and music with her physical ears. In addition, the veridical nature of these perceptions, together with the uncertainty she was unconscious throughout the whole procedure, mean that she heard these things during periods of awareness. So how did she hear each of these four different veridical episodes? I will answer this question by discussing each of these veridical observations in the order they occurred.

1) The first sound Reynolds mentioned was awakening to the sound of a "natural D." This was the sound of the pneumatic drill used to make an initial hole in the skull through which the bone saw could subsequently be introduced. The rotations of the drill generated vibrations at a frequency that Reynolds, a musician, recognized as a "natural D." This sound was not heard though the ears, and it would have been heard regardless of even totally soundproof earplugs. It was transmitted through the bones of her skull to her cochleae that transformed the vibrations into the sound she heard. I contend that this was how she heard the sound of the drill. Note that Reynolds made absolutely no mention of hearing clicking sounds in one of her ears at the time of hearing the drill. Note also that while Reynolds was conscious and aware, she felt calm, felt more awake than normal, and felt no pain-due presumably to the effects of the Sufentanil and nitrous oxide.

2) The buzzing sound of the pneumatic saw was the next sound she perceived. The saw was introduced through the starting hole in her skull to make an opening through which Spetzler could operate upon her aneurysm. I contend that the motions of the saw vibrating the skull produced the buzzing sound. Just as with the sound of the drill, the sound of the saw was conducted through 
the bones of Reynolds' skull directly to her cochleae. Likewise, she also did not hear this sound through her ears-and she would have heard this bone-conducted sound regardless of even totally soundproof earplugs. I believe that this was how she heard the sound of the saw. Here again, even though Reynolds was conscious and aware, she felt calm, felt more awake than normal, and felt no pain-due presumably to the effects of the Sufentanil and nitrous oxide. Note also that Reynolds made absolutely no mention of hearing clicking sounds in one of her ears at the time of hearing the bone saw.

3) The next veridical sound Reynolds heard was the comment the cardiothoracic surgeon made about the blood vessels in Reynolds' right groin being too small for the cardiac bypass tubing. This was a sound transmitted through the air to her ears and was verifiably heard by Reynolds. Normal speech has an intensity of about 60 decibels. I discussed earlier how her ability to hear with one ear was almost normal despite the clicking sounds, while the opposite ear was fed a masking white sound at an intensity of 40 decibels. Consequently, the BAEP stimuli did not block her ability to hear with her ears. The only other possible factor limiting her hearing was the earphones, but nothing is known of the soundreduction properties of these earphones. No mention is made of this matter in publications about the hypothermia surgical procedure (Raudzens, 1982; Spetzler et al., 1988). However, the fact that Reynolds did hear these sounds indicates the earplugs did not totally block out all sounds. Once again, even though Reynolds was conscious and aware, she felt calm, felt more awake than normal, and felt no pain-due presumably to the effects of the Sufentanil and nitrous oxide (see also Woerlee 2004, 2005b).

Another aspect of this veridical perception is that the anesthetic drugs had evidently affected Reynolds' mental function, because she reported at the time of the perception that she knew her groin blood vessels were too small for the bypass tubing. She said, "Someone said something about my veins and arteries being very small. I believe it was a female voice . . . I remember thinking that I should have told her about that. ..." I find this passage to be very revealing. After all, who knows the sizes of their groin blood vessels? I believe that this was how Pam Reynolds heard the comments of the cardiothoracic surgeon and the explanation of her reaction to hearing these words. Note also that Pam Reynolds made absolutely no mention of hearing clicking sounds in one of her ears at the time of hearing Murray speak those words.

4) Lastly, Reynolds reported hearing the song Hotel California during the period her wounds were being closed. This was a verifiable event indicating she heard the music. Music played at normal 
levels has a sound intensity varying between $60-85$ decibels. The considerations are otherwise the same as during the period she heard the cardiothoracic surgeon comment on the size of her groin blood vessels. Note once again that even though Reynolds was conscious and aware, she felt calm, felt more awake than normal, and felt no pain-due presumably to the effects of the Sufentanil and nitrous oxide. Moreover, Reynolds' reaction to hearing the song indicates an implicit reference to the paralyzing effects of the drug vecuronium. This is a muscle-paralyzing drug similar to curare. It does not affect mental function in any way but does paralyze all voluntary muscles, so a person paralyzed by vecuronium may try to move, but no amount of effort results in any movement. This drug effect was why she found the line, "You can check out anytime you like, but you can never leave," incredibly insensitive. I contend that this was how Pam Reynolds heard the song Hotel California as it was playing and how she reacted to hearing the music. Note once again, that Pam Reynolds made absolutely no mention of hearing clicking sounds in one of her ears at the time of hearing the song.

Nowhere in the otherwise excellent account of the Pam Reynolds experience is there any mention of her hearing the clicking sounds of the BAEP stimuli in the ear to which it was applied. Yet there is mention that the BAEP was used to determine her level of consciousness throughout her operation, clearly indicating that these stimuli were correctly applied. This discrepancy indicates that she ignored these clicking sounds, much as people typically ignore engine noise in an automobile or airplane.

\section{Concluding Remarks}

The well-known experience of Pam Reynolds is extraordinary and appears superficially to be wondrous proof of the separable nature of the conscious mind. Yet careful examination of the facts of Sabom's (1998) excellent report and the details of the procedure as published by Spetzler et al. (1988) reveal the nature of this experience to be different than it initially appears. This discussion of how she could hear the four episodes of veridical sounds, speech, and music is but one aspect of the explanation of her experience. As stated earlier, other aspects have been published in earlier articles. So her experience, while wondrous, is one whose explanation is rooted in the functioning of the human mind, the effects of a surgical technique, and the mental manifestations of drugs used to provide general anesthesia, and possibly the inadequate monitoring of consciousness. Even so, the experience, 
while explicable with natural phenomena, does reveal many facets of the functioning of the human mind during anesthesia and surgery, as well as the deepest hopes and fears of one person, Pam Reynolds.

\section{References}

Andrade, J. (2005). Does memory priming during anesthesia matter? Anesthesiology, 103, 1-2.

Artusio, J. F. (1954). Di-ethyl ether analgesia: A detailed description of the first stage of ether anesthesia in man. Journal of Pharmacology and Experimental Therapeutics, 111, 343-348.

ASA, (2006), Practice advisory for intraoperative awareness and brain function monitoring. Anesthesiology, 104, 847-864.

Bond, A. E., Zada, G., Gonzalez, A. A., Hansen, C., \& Giannottaa, S. L. (2010). Operative strategies for minimizing hearing loss and other major complications associated with microvascular decompression for trigeminal neuralgia. World Neurosurgery, 74, 172-177.

Broome, K. (Producer). (2002). The day I died: The mind, the brain, and neardeath experiences [Motion picture]. Princeton, NJ: Films for the Humanities and Sciences.

Buchanan, F. F., Myles, P. S., \& Cicuttini, F. (2011). Effect of patient sex on general anaesthesia and recovery. British Journal of Anaesthesia, 106, 832-839.

Cobbe, W. R. (1895). Doctor Judas: A portrayal of the opium habit. Chicago, IL: S. C. Griggs

Dahan A, (2009), The importance of individual differences in response to opioid therapy. Therapy, 6, 633-635.

Davy, H. (1800). Researches, chemical and philosophical; Chiefly concerning nitrous oxide, or depholgisticated nitrous airs and its respiration. Bristol, England: Biggs and Cottle.

Drummond, J. C., Todd, M. M., \& Sang, H. (1985). The effect of high dose sodium thiopental on brain stem auditory and median nerve somatosensory evoked responses in humans. Anesthesiology, 63, 249-254.

Fenwick, P., \& Fenwick, E. (1996). The truth in the light. London, England: Headline.

Gedney, J. A., \& Ghosh, S. A. (1995). Pharmacokinetics of analgesics, sedatives and anaesthetic agents during cardiopulmonary bypass. British Journal of Anaesthesia, 75, 344-351.

Ghoneim, M. M., \& Block, R. I. (1992). Learning and consciousness during general anesthesia. Anesthesiology, 76, 279-305.

Haba, M., Tajima, T., \& Kinoshita, H. (2011, June). The evaluation of symptoms related to remifentanil effect-site concentrations in humans. Poster presentation at the 14th Eurosiva Annual Meeting, Amsterdam, The Netherlands.

Han, P. P., O'Neill, B., \& Spetzler, R.F. (2003). Surgical management of giant arteriovenous malformation. Operative Techniques in Neurosurgery, 6, 95-99.

Holden, J. M. (2009). Veridical perception in near-death experiences. In J. M. Holden, B. Greyson, \& D. James (Eds.), The handbook of near-death experiences: Thirty years of investigation (pp. 185-212). Santa Barbara, CA: Praeger/ ABC-CLIO.

Hughes, M.A., Glass, P.S.A., Jacobs, J.R. (1992). Context-sensitive half-time in 
multicompartment pharmacokinetic models for intravenous anesthetic drugs, Anesthesiology, 76, 334-341.

Iselin-Chaves, I. A., Willems, S. J., Jermann, F. C., Forster, A., Adam, S. R., \& Van der Linden, M. (2005). Investigation of implicit memory during Isoflurane anesthesia for elective surgery using the process dissociation procedure. Anesthesiology, 103, 925-933.

James, W. (1912). The will to believe: And other essays in popular philosophy. New York, NY: Longmans, Green. (Original work published 1896)

Jones, J. G. (1994). Perception and memory during general anaesthesia. British Journal of Anaesthesia, 73, 31-37.

Lasagna, L., von Felsinger, J. M., \& Beecher, H. K. (1955). Drug-induced mood changes in man. 1. Observations on healthy subjects, chronically ill patients, and "post-addicts". Journal of the American Medical Association, 157, 1006-1020.

Loveman, E., van Hooff, J. C., \& Smith, D. C. (2001). The auditory evoked response as an awareness monitor during anaesthesia. British Journal of Anaesthesia, 86, 513-518.

Kerssens, C., Ouchi, T., \& Sebel, P. (2005). No evidence of memory function during anesthesia with propofol or isoflurane with close control of hypnotic state. Anesthesiology, 102, 57-62.

Matalanis, G., Hata, M., \& Buxton, B. F. (2003). A retrospective comparative study of deep hypothermic circulatory arrest, retrograde, and antegrade cerebral perfusion in aortic arch surgery. Annals of Thoracic and Cardiovascular Surgery, 9, 174-179.

Orser, B. A., Mazer, C. D., \& Baker, A. J. (2008), Awareness during anesthesia. Canadian Medical Association Journal, 178, 185-188.

Raudzens, P. A. (1982). Intraoperative monitoring of evoked potential. Annals of the New York Academy of Sciences, 388, 308-325.

Ring, K., \& Lawrence, M. (1993). Further evidence for veridical perception during near-death experiences. Journal of Near-Death Studies, 11, 223-229.

Sabom, M. B. (1982). Recollections of death: A medical investigation. New York, NY: Harper Collins.

Sabom, M. B. (1998). Light \& death: One doctor's fascinating account of neardeath experiences. Grand Rapids, MI: Zondervan.

Spencer, F. C., \& Bahnson, H. T. (1962). The present role of hypothermia in cardiac surgery. Circulation, 26, 292-300.

Schneider, G., Nahm, W., Kochs, E. F., Bischoff, C. J., Kalkman, H. K., \& Thornton, C. (2003), Quality of perioperative AEP - variability of expert ratings. British Journal of Anaesthesia, 91, 905-908.

Sebel, P. S., Bowdle, T. A., Ghoneim, M. M., Rampil, I. J., Padilla, R. E., Gan, T. J., \& Domino, K. B. (2004). The incidence of awareness during anesthesia: A multicenter United States study. Anesthesia \& Analgesia, 99, 833-839.

Spetzler, R. F., Hadley, M. N., Rigamonti, D., Carter, L. P., Raduzens, P. A., Shedd, S. A., \& Wilkinson, E. (1988). Aneurysms of the basilar artery treated with circulatory arrest, hypothermia, and barbiturate cerebral protection. Journal of Neurosurgery, 68, 868-879.

Thornton, C., \& Sharpe, R. M. (1998). Evoked responses in anaesthesia. British Journal of Anaesthesia, 81, 771-781.

Tiberi, E. (1993). Extrasomatic emotions. Journal of Near-Death Studies, 11, 149-170. 
Woerlee, G. M. (2004). Pam Reynolds: Ein Nahtodeserlebnis aus der Sicht eines Anästhesisten [A near-death experience from the viewpoint of an anesthetist]. Skeptiker, 4, 144-150.

Woerlee, G. M. (2005a). An anaesthesiologist examines the Pam Reynolds story; Part 1: Background considerations. The Skeptic, 18, 14-17.

Woerlee, G. M. (2005b). An anaesthesiologist examines the Pam Reynolds story; Part 2: The experience. The Skeptic, 18, 16-20.

Woerlee, G. M, (2005c). Mortal minds: The biology of near-death experiences. Amherst, NY: Prometheus Books.

Woerlee, G. M. (2010). Response to "Corroboration of the Dentures Anecdote Involving Veridical Perception in a Near-Death Experience." Journal of Near Death Studies, 28, 181-191.

Woerlee, G. M. (2011). Narcothymia: The illusory soul. Manuscript in process.

\section{Addendum: A Demonstration of Hearing During Pam Reynolds' Operation}

The possibility that Pam Reynolds heard through normal means the sounds she reported having heard during her 1991 surgery is readily determined with a surprisingly simple test. This test is available to anyone with an internet connection, a computer running the Windows ${ }^{\circledR}$ operating system, a good sound card, and good quality earphones or earplugs. The test uses a program called "Test Tone Generator," which is a shareware program providing a 30-day free trial. With this program it is possible to emulate the auditory stimuli used to induce BAEPs during Reynolds' general anesthesia and operation. Unfortunately, this program works only on PCs, not on Macintosh / Apple computers

\section{Downloading and installing the program}

Website for download: http://www.esseraudio.com/en/home.html

- Select in the software menu left: Test Tone Generator.

- Select in the software menu left: Download.

- Select either an EXE-file or a ZIP-file from one of the four download servers. If you have a Windows ${ }^{\circledR}$ machine, my advice is to use the EXE-file option. It is quicker, and you avoid the intermediate step of unpacking a ZIP-file.

- Ignore the Windows ${ }^{\circledR}$ complaints about this being an unknown file and program, and accept the program.

- Run the installation program.

The result is a 30-day trial of a program called "Test Tone Generator." 


\section{Emulating Audio Parameters Used in Pam Reynolds' Operation}

What are the stimulus parameters to emulate with this program?

- One ear: white noise at a volume of $40 \mathrm{~dB}$.

- Other ear: square waves at a volume of $95 \mathrm{~dB}$.

- Square wave pulse duration of $0.1 \mathrm{msec}$.

Instructions for setting up the parameters in Test Tone Generator, going from left to right, and top to bottom:

- Output device: Windows default, or communcations headphone

- Period: this can be any preferred length of time in seconds.

- Channels: stereo

- Left Channel: on

- Right Channel: on,

- Do not select: Same as Left

- Wave Function (left): White noise

- Wave Function (right): Square (unfortunately it is impossible to adjust the duration of the square wave pulse with this program, but this is actually irrelevant for the purpose of this test. In fact, this setting actually makes it more difficult to hear external sounds)

- Under White Noise, select Crest Factor: 1.42:1 (this is also a default)

- Under Frequency on the right side, select: $11 \mathrm{~Hz}$, with "Constant". (do not select "Sweep")

- Do not select "Amplitude Modulation" for either ear.

- Under Amplitude for the left ear, (white noise), select: -60 dBFS, this will provide $40 \mathrm{~dB}$ white noise. (NB. dBFS is a term meaning "decibels relative to full scale," which is a way of expressing decibels in digital sound systems. A dBFS level $=0$, is the maximum possible volume, and $\mathrm{dBFS}=100$, is the lowest possible volume).

- Under Amplitude for the right ear, (square waves), select: -5 dBFS. This setting will provide $95 \mathrm{~dB}$ square wave pulses in the right ear.

\section{Earphones and Computer Volume Control}

The next part of the test requires a simple adjustment of the computer sound volume. Go to the sound volume adjustment of the computer, and set the volume control at maximum.

Unfortunately the sound reducing properties of the actual earphones used in the Reynolds case are not known, so all that can be done is to compromise with earphones or earplugs that significantly reduce ambient sound levels. This can be done in one of two ways. 
- Plug in a set of good quality clamshell, (or circumaural), earphones. These are earphones with soft cushions around the edges, completely covering the ears and excluding external sounds to a greater or lesser degree depending upon quality of manufacture.

- Otherwise use good quality earplugs of the type with soft rubber ear inserts that totally occlude the ear canals.

\section{The Test}

The rest of the procedure is evident.

- Turn on the Test Tone Generator sound and listen to the music of "Hotel California" at a volume appropriate for cheerful working conditions. This means music played at a moderately to quite loud volume at a distance of about 5 meters (5 yards).

- Turn on the Test Tone Generator sound and listen to the sound of someone reading aloud from a newspaper or book from a distance of 2 meters (6 feet), at a speech volume appropriate to attracting attention, or working in a noisy environment.

You will notice it is possible to hear the sounds of speech and the music of "Hotel California" without any difficulty. This test outcome indicates that Pam Reynolds was well able to hear the sounds of speech and music during a period of awareness during her operation. 